Pacific Journal of Mathematics

BOUNDS FOR PRODUCTS OF INTERVAL FUNCTIONS 


\title{
BOUNDS FOR PRODUCTS OF INTERVAL FUNCTIONS
}

\author{
JoN C. HeLtoN
}

\begin{abstract}
Since it is possible for ${ }_{a} \Pi^{b}(1+G)$ to exist and not be zero when $G$ is unbounded and $1+G$, is not bounded away from zero, the conditions under which products of the form $\left|\Pi_{1}^{n}\left[1+G\left(x_{q-1}, x_{q}\right)\right]\right|$ are bounded or bounded away from zero for suitable subdivisions $\left\{x_{q}\right\}_{0}^{n}$ of $[a, b]$ are important in many theorems concerning product integrals. Conditions are obtained for such bounds to exist for products of the form $\Pi(1+F G)$ and $\Pi(1+F+G)$, where $F$ and $G$ are functions from $R \times R$ to $R$. Further, these results are used to obtain an existence theorem for product integrals.
\end{abstract}

All integrals and definitions are of the subdivision-refinement type, and functions are from the subset $\{(x, y): x<y\}$ of $R \times R$ to $R$, where $R$ represents the set of real numbers. If $D=\left\{x_{q}\right\}_{0}^{n}$ is a subdivision of $[a, b]$ and $G$ is a function, then $D(I)=\left\{\left[x_{q-1}, x_{q}\right]\right\}_{1}^{n}$ and $G_{q}=$ $G\left(x_{q-1}, x_{q}\right)$. The statements that $G$ is bounded, $G \in O P^{\circ}, G \in O Q^{\circ}$ and $G \in O B^{\circ}$ on $[a, b]$ mean there exist a subdivision $D$ of $[a, b]$ and a positive number $B$ such that if $J=\left\{x_{q}\right\}_{0}^{n}$ is a refinement of $D$, then

(1) $|G(u)|<B$ for $u \in J(I)$,

(2) $\left|\Pi_{r}^{s}\left(1+G_{q}\right)\right|<B$ for $1 \leqq r \leqq s \leqq n$,

(3) $\left|\Pi_{r}^{s}\left(1+G_{q}\right)\right|>B$ for $1 \leqq r \leqq s \leqq n$, and

(4) $\Sigma_{J(I)}|G|<B$,

respectively. The notation $\left\{x_{q r}\right\}_{0}^{n(q)}$ represents a subdivision of an interval $\left[x_{q-1}, x_{q}\right]$ defined by a subdivision $\left\{x_{q}\right\}_{0}^{n}$. If $G$ is a function, then $G \in S_{1}$ on $[a, b]$ only if $\lim _{x, y \rightarrow p}+G(x, y)$ and $\lim _{x, y \rightarrow p}-G(x, y)$ exist and are zero for $p \in[a, b]$, and $G \in S_{2}$ on $[a, b]$ only if $\lim _{x \rightarrow p}+G(p, x)$ and $\lim _{x \rightarrow p}-G(x, p)$ exist for $p \in[a, b]$. Further, $G \in O A^{\circ}$ on $[a, b]$ only if $\int_{a}^{b} G$ exists and $\int_{a}^{b}\left|G-\int G\right|=0$, and $G \in O M^{\circ}$ on $[a, b]$ only if ${ }_{x} \Pi^{y}(1+G)$ exists for $a \leqq x<y \leqq b$ and $\int_{a}^{b}|1+G-\Pi(1+G)|=0$. Also, $G \in O Q^{1}$ and $G \in O B^{*}$ on $[a, b]$ if there exists a subdivision $D=$ $\left\{x_{q}\right\}_{0}^{n}$ of $[a, b]$ such that

and

(1) if $1 \leqq q \leqq n$ and $x_{q-1}<x<y<x_{q}$, then $G \in O Q^{\circ}$ on $[x, y]$,

(2) if $1 \leqq q \leqq n$, then either $G \in O B^{\circ}$ on $\left[x_{q-1}, x_{q}\right]$ or $G-1 \in O B^{\circ}$ on $\left[x_{q-1}, x_{q}\right]$,

respectively. The statement that $G$ is almost bounded above by $\beta$ (or, almost bounded below by $\beta$ ) on $[a, b]$ means there exists a positive integer $N$ such that if $D$ is a subdivision of $[a, b]$ and $u \in H$ only if $u \in D(I)$ and $G(u)>\beta$ (or, $G(u)<\beta$ ) then $H$ has less than $N$ elements. Consult B. W. Helton [2] and J. S. MacNerney [4] for 
additional details.

THEOREM 1. If $G$ is a function, then the following are equivalent:

(1) $G \in O B^{\circ}$ on $[a, b]$, and

(2) if $F \in O P^{\circ}$ on $[a, b]$, then $F+G \in O P^{\circ}$ on $[a, b]$.

Proof $(2 \rightarrow 1)$. Let $F$ be the function such that $F(x, y)=0$ if $G(x, y) \geqq 0$ and $F(x, y)=-2$ if $G(x, y)<0$. Hence, if $J$ is a subdivision of $[a, b]$, then

$$
\left|\Pi_{J(I)}(1+F+G)\right|=\Pi_{J(I)}(1+|G|),
$$

which can be bounded only if $G \in O B^{\circ}$.

Proof $(1 \rightarrow 2)$. Suppose $F \in O P^{\circ}$. There exist positive numbers $B$ and $C$ with $B>1$, a positive integer $i$ and a subdivision $D$ of $[a, b]$ such that if $J=\left\{x_{q}\right\}_{0}^{w}$ is a refinement of $D$, then

(1) $\left|\Pi_{r}^{s}\left(1+F_{q}\right)\right|<B$ for $1 \leqq r \leqq s \leqq w$,

(2) $\exp \left[4 B \Sigma_{J(I)}|G|\right]<C$,

(3) if $T$ is a collection of nonintersecting subsets of $J(I)$, then the number of $t \in T$ such that $\exp \left[4 B \Sigma_{t}|G|\right]>2$ is less than $i$, and

(4) the number of $u \in J(I)$ such that $|G(u)|>1 / 4 B$ is less than $i$.

Let $J=\left\{x_{q}\right\}_{0}^{w}$ be a refinement of $D$ and suppose $1 \leqq r \leqq s \leqq w$. Let $L=\left\{\left[x_{q-1}, x_{q}\right]\right\}_{r}^{\text {s }}$, and let $H$ be the subset of $L$ such that $u \in H$ only if $|1+F(u)| \leqq 1 / 4 B$. Further, let $K$ be the collection of subsets of $L$ such that $k \in K$ only if there exist $u, v \in H$ such that $u$ precedes $v$ on $[a, b]$ and either

(1) $k=\{t \mid t$ precedes $v$ and follows $u\}$ and $k \cap H=\varnothing$,

(2) $u$ is the first element in $H$ and $k=\{t \mid t$ precedes $u\}$, or

(3) $v$ is the last element in $H$ and $k=\{t \mid t$ follows $v\}$. Let $u \in M$ only if $u \in H$ and $|G(u)|>1 / 4 B$, and let $k \in N$ only if $k \in K$ and $\exp \left[4 B \Sigma_{k}|G|\right]>2$. Hence, $M$ and $N$ each has less than $i$ elements. Also, $K$ has at most one more element than $H$. Hence, $K-N$ can have at most $i$ more elements than $H-M$. Let $j, m$ and $n$ denote the number of elements in $M, H-M$ and $K-N$, respectively, and suppose $U=\bigcup_{k \in K} k$. Hence,

$$
\begin{aligned}
& \left|\Pi_{L}(1+F+G)\right| \\
& \quad \leqq\left\{\Pi_{H}[|1+F|+|G|]\right\} \cdot\left\{\left|\Pi_{U}(1+F+G)\right|\right\} \\
& \quad \leqq\left\{\Pi_{M}[1 / 4 B+|G|]\right\} \cdot\left\{\Pi_{H-M}[1 / 4 B+|G|]\right\} \cdot\left\{\left|\Pi_{U}(1+F+G)\right|\right\} \\
& \quad \leqq\left\{(1 / 4 B)^{j} C\right\} \cdot\{1 / 4 B+1 / 4 B\}^{m} \cdot\left\{\left|\Pi_{U}(1+F+G)\right|\right\} \\
& \quad \leqq C\{1 / 2 B\}^{m} \cdot\left\{\Pi_{k \in K}\left|\Pi_{k}[1+F]\left[1+(1+F)^{-1} G\right]\right|\right\} \\
& \quad \leqq C\{1 / 2 B\}^{m} \cdot\left\{\Pi_{k \in K}\left[\left|\Pi_{k}(1+F)\right|\right]\left[\Pi_{k}(1+4 B|G|)\right]\right\} \\
& \quad=C\{1 / 2 B\}^{m} \cdot\left\{\Pi_{k \in N}\left[\left|\Pi_{k}(1+F)\right|\right]\left[\Pi_{k}(1+4 B|G|)\right]\right\} .
\end{aligned}
$$




$$
\begin{aligned}
& \left\{\Pi_{k \in K-N}\left[\left|\Pi_{k}(1+F)\right|\right]\left[\Pi_{k}(1+4 B|G|)\right]\right\} \\
& \quad \leqq C\{1 / 2 B\}^{m} \cdot\{B C\}^{i} \cdot\{2 B\}^{n} \\
& \quad=B^{i} C^{i+1}(2 B)^{n-m} \leqq B^{i} C^{i+1}(2 B)^{i}
\end{aligned}
$$

LEMMA 1.1. If $\int_{a}^{b} F$ exists, then $F \in O A^{\circ}$ on $[a, b]$.

This result is due to A. Kolmogoroff [3, p. 669]. Further, related results have also been obtained by W. D. L. Appling [1, Th. 2, p. 155] and B. W. Helton [2, Th. 4.1, p. 304].

COROLLARY 1.1. If $\int_{a}^{b} F$ exists, then the following are equivalent: (1) $F \in O P^{\circ}$ on $[a, b]$, and (2) $\int F \in O P^{\circ}$ on $[a, b]$.

Indication of proof. Since $\int_{a}^{b} F$ exists, $F \in O A^{\circ}$ [Lemma 1.1]. The result now follows by using Theorem 1 .

CoRollary 1.2. If $F \in O P^{\circ}$ on $[a, b],{ }_{a} \Pi^{b}(1+F)$ exists and $\int_{a}^{b}|G|=0$, then ${ }_{a} \Pi^{b}(1+F+G)$ exists and is ${ }_{a} \Pi^{b}(1+F)$.

Indication of proof. A related result is proved by B. W. Helton [2, Th. 5.6, p. 315]. This result follows by an argument similar to the one used in that theorem since Theorem 1 implies that $F+G \in O P^{\circ}$.

COROLlaRY 1.3. If $G$ is a function, then the following are equivalent:

(1) $G \in O P^{\circ}$ on $[a, b]$, and

(2) if $F \in O B^{\circ}$ on $[a, b]$, then $F+G \in O P^{\circ}$ on $[a, b]$.

Proof. Theorem 1 establishes that (1) implies (2). Further, (2) implies (1) since $F \equiv 0$ belongs to $O B^{\circ}$.

B. W. Helton has shown if $G$ is a function from $S \times S$ to $N$ such that $G \in O A^{\circ}$ and $G \in O B^{\circ}$, then $G \in O M^{\circ}$, where $S$ represents a linearly ordered set and $N$ represents a ring which has a multiplicative identity element denoted by 1 and has a norm $|\cdot|$ with respect to which $N$ is complete and $|1|=1$ [2, Th. $3.4(1 \rightarrow 2)$, p. 301]. We now use Theorem 1 to establish a related result. In particular, we show that if $F$ and $G$ are functions from $R \times R$ to $R$ such that $F \in O M^{\circ}$, $F \in O P^{\circ}, F \in S_{1} \cap S_{2}$ and $G \in O B^{\circ}$ on $[a, b]$ and $\int_{a}^{b} G$ exists, then $F+$ $G \in O M^{\circ}$ on $[a, b]$.

LEMma 2.1. If $F$ and $G$ are functions such that $F \in O M^{\circ}, F \in$ 
$O P^{\circ}, F \in S_{1}$ and $G \in O B^{\circ}$ on $[a, b]$ and $\varepsilon>0$, then there exists a subdivision $\left\{y_{q}\right\}_{0}^{u}$ of $[a, b]$ such that if $y_{q-1}<x<y<y_{q}$ and $H$ is a subdivision of $[x, y]$, then

$$
\left|1-\Pi_{H(I)}(1+F+G)\right|<\varepsilon .
$$

Further, if $F \in S_{2}$ and $G \in S_{2}$ on $[a, b]$, then there exists a subdivision $\left\{z_{q}\right\}_{0}^{v}$ of $[a, b]$ such that if $z_{q-1} \leqq x<y \leqq z_{q}$ and $H$ is a subdivision of $[x, y]$, then

$$
\left|1+F(x, y)+G(x, y)-\Pi_{H(I)}(1+F+G)\right|<\varepsilon .
$$

Proof. Suppose $F$ and $G$ are functions such that $F \in O M^{\circ}, F \in$ $O P^{\circ}, F \in S_{1}$ and $G \in O B^{\circ}$ on $[a, b]$ and $\varepsilon>0$. It follows from Theorem 1 that $F+G \in O P^{\circ}$. There exist a subdivision $D_{1}=\left\{y_{q}\right\}_{0}^{u}$ of $[a, b]$ and a number $B>1$ such that if $J=\left\{x_{q}\right\}_{0}^{n}$ is a refinement of $D_{1}$, then

(1) $\left|\Pi_{i}^{j}\left(1+F_{q}\right)\right|<B$ and $\left|\Pi_{i}^{j}\left(1+F_{q}+G_{q}\right)\right|<B$ for $1 \leqq i \leqq j \leqq n$,

(2) $|F(x, y)|<\varepsilon / 9 B$ and $\Sigma_{H(I)}|G|<\varepsilon / 9 B^{3}$ if $1 \leqq q \leqq n, x_{q-1}<$ $x<y<x_{q}$ and $H$ is a subdivision of $[x, y]$, and

(3) $\Sigma_{q}\left|\left(1+F_{q}\right)-\Pi_{H_{q}(I)}(1+F)\right|<\varepsilon / 9 B$, where $H_{q}$ is a subdivision of $\left[x_{q-1}, x_{q}\right]$ for $q=1,2, \cdots, n$.

Suppose $1 \leqq q \leqq u$ and $y_{q-1}<x<y<y_{q}$. If $H=\left\{h_{q}\right\}_{0}^{r}$ is a subdivision of $[x, y]$, then

$$
\begin{aligned}
\mid 1- & \Pi_{H(I)}(1+F+G) \mid \\
= & \mid 1+F(x, y)-F(x, y)-\left\{\Pi_{q=1}^{r}\left(1+F_{q}\right)\right. \\
& \left.+\sum_{q=1}^{r}\left[\Pi_{j=1}^{q-1}\left(1+F_{j}\right)\right]\left[G_{q}\right]\left[\Pi_{k=q+1}^{r}\left(1+F_{k}+G_{k}\right)\right]\right\} \mid \\
\leqq & \left|1+F(x, y)-\Pi_{q=1}^{r}\left(1+F_{q}\right)\right|+|F(x, y)| \\
& +\sum_{q=1}^{r}\left|\Pi_{j=1}^{q-1}\left(1+F_{j}\right)\right|\left|G_{q}\right|\left|\Pi_{k=q+1}^{r}\left(1+F_{k}+G_{k}\right)\right| \\
< & \varepsilon / 9 B+\varepsilon / 9 B+B^{2} \varepsilon / 9 B^{3}=\varepsilon / 3 B<\varepsilon .
\end{aligned}
$$

We now make the additional suppositions that $F \in S_{2}$ and $G \in S_{2}$ on $[a, b]$. There exists a subdivision $E=\left\{w_{q}\right\}_{0}^{2 u+1}$ of $[a, b]$ such that

(1) $y_{q} \in\left(w_{2 q}, w_{2 q+1}\right)$ for $1 \leqq q<u$,

(2) $\left|F\left(y_{q}, w_{2 q+1}\right)+G\left(y_{q}, w_{2 q+1}\right)-F\left(y_{q}, x\right)-G\left(y_{q}, x\right)\right|<\varepsilon / 2$ for $0 \leqq$ $q<u$ and $x \in\left(y_{q}, w_{2 q+1}\right]$, and

(3) $\left|F\left(w_{2 q}, y_{q}\right)+G\left(w_{2 q}, y_{q}\right)-F\left(x, y_{q}\right)-G\left(x, y_{q}\right)\right|<\varepsilon / 2$ for $0<q \leqq$ $u$ and $x \in\left[w_{2 q}, y_{q}\right)$.

Let $D_{2}=\left\{z_{q}\right\}_{0}^{3 u}$ be the subdivision $D_{1} \cup E$ of $[a, b]$. Suppose $1 \leqq q \leqq 3 u$, $z_{q-1} \leqq x<y \leqq z_{q}$ and $H$ is a subdivision of $[x, y]$. If either $z_{q-1}<$ $x<y<z_{q}$ or neither $z_{q-1}$ nor $z_{q}$ is in $D_{1}$, then

$$
\begin{aligned}
& \left|1+F(x, y)+G(x, y)-\Pi_{H(I)}(1+F+G)\right| \\
& \quad \leqq|F(x, y)|+|G(x, y)|+\left|1-\Pi_{H(I)}(1+F+G)\right| \\
& \quad<\varepsilon / 9 B+\varepsilon / 9 B^{3}+\varepsilon / 3 B<\varepsilon .
\end{aligned}
$$


If $z_{q-1} \in D_{1}, x=z_{q-1}$ and $H=\left\{h_{q}\right\}_{0}^{r}$, then

$$
\begin{aligned}
\mid 1+ & F(x, y)+G(x, y)-\Pi_{H(I)}(1+F+G) \mid \\
\leqq & \left|F(x, y)+G(x, y)-F\left(x, h_{1}\right)-G\left(x, h_{1}\right)\right| \\
& +\left|1+F\left(x, h_{1}\right)+G\left(x, h_{1}\right)\right| \mid 1-\Pi_{2}^{r}\left[1+F\left(h_{q-1}, h_{q}\right)\right. \\
& \left.+G\left(h_{q-1}, h_{q}\right)\right] \mid \\
& <\varepsilon / 2+B \varepsilon / 3 B<\varepsilon .
\end{aligned}
$$

If $z_{q} \in D_{1}$ and $y=z_{q}$, the necessary inequality follows in a similar manner. Therefore, $D_{2}$ is the desired subdivision.

THEOREM 2. If $F$ and $G$ are functions such that $F \in O M^{\circ}, F \in$ $O P^{\circ}, F \in S_{1} \cap S_{2}$ and $G \in O B^{\circ}$ on $[a, b]$ and $\int_{a}^{b} G$ exists, then $F+G \in$ $O M^{\circ}$ on $[a, b]$.

Proof. We initially show that if $\varepsilon>0$ then there exists a subdivision $D$ of $[a, b]$ such that if $H=\left\{x_{q}\right\}_{0}^{n}$ is a refinement of $D$ and $H_{q}$ is a subdivision of $\left[x_{q-1}, x_{q}\right]$ for $q=1,2, \cdots, n$, then

$$
\Sigma_{1}^{n}\left|1+F_{q}+G_{q}-\Pi_{H_{q}(I)}(1+F+G)\right|<\varepsilon .
$$

Let $\varepsilon>0$. It follows from Lemma 1.1 that $G \in O A^{\circ}$ and from Theorem 1 that $F+G \in O P^{\circ}$. Thus, by employing the hypothesis and Lemma 2.1, there exist a subdivision $D_{1}=\left\{y_{q}\right\}_{0}^{u}$ of $[a, b]$ and a number $B>1$ such that if $J=\left\{x_{q}\right\}_{0}^{n}$ is a refinement of $D_{1}$, then

(1) $\Sigma_{J(I)}|G|<B$,

(2) $\left|\Pi_{i}^{j}\left(1+F_{q}\right)\right|<B$ for $1 \leqq i \leqq j \leqq n$,

(3) $\Sigma_{1}^{n}\left|G_{q}-\Sigma_{L_{q}(I)} G\right|<\varepsilon / 5$ and $\Sigma_{1}^{n}\left|\left(1+F_{q}\right)-\Pi_{L_{q}(I)}(1+F)\right|<\varepsilon / 5$, where $L_{q}$ is a subdivision of $\left[x_{q-1}, x_{q}\right]$ for $1 \leqq q \leqq n$, and

(4) $\left|1-\Pi_{H(I)}(1+F)\right|<\varepsilon / 5 B$ and $\left|1-\Pi_{H(I)}(1+F+G)\right|<\varepsilon / 5 B^{2}$ for $1 \leqq q \leqq n, x_{q-1}<x<y<x_{q}$ and $H$ a subdivision of $[x, y]$.

Further, it also follows from Lemma 2.1 that there exists a subdivision $D_{2}=\left\{z_{q}\right\}_{0}^{v}$ of $[a, b]$ such that if $1 \leqq q \leqq v, z_{q-1} \leqq x<y \leqq z_{q}$ and $H$ is a subdivision of $[x, y]$, then

$$
\left|1+F(x, y)+G(x, y)-\Pi_{H(I)}(1+F+G)\right|<\varepsilon / 10 u \text {. }
$$

Let $D=D_{1} \cup D_{2}$, and suppose $H=\left\{x_{q}\right\}_{0}^{n}$ is a refinement of $D$ and $H_{q}=\left\{x_{q r}\right\}_{0}^{n(q)}$ is a subdivision of $\left[x_{q-1}, x_{q}\right]$ for $1 \leqq q \leqq n$. Let $P$ be the set such that $q \in P$ only if $\left[x_{q-1}, x_{q}\right]$ has an end point in $D_{1}$, and let $Q=\{i\}_{1}^{n}-P$. Further, to simplify notation, let $F_{q r}=F\left(x_{q, r-1}, x_{q r}\right)$, $G_{q r}=G\left(x_{q, r-1}, x_{q r}\right), A_{q r}=\Pi_{j=1}^{r-1}\left(1+F_{q j}\right)$ and $B_{q r}=\prod_{k=r+1}^{n(q)}\left(1+F_{q k}+G_{q k}\right)$. Thus,

$$
\begin{aligned}
& \sum_{q=1}^{n}\left|1+F_{q}+G_{q}-\Pi_{H_{q}(I)}(1+F+G)\right| \\
& \quad \leqq \Sigma_{q \in P}\left|1+F_{q}+G_{q}-B_{q 0}\right|
\end{aligned}
$$




$$
\begin{aligned}
& +\Sigma_{q \in Q}\left|1+F_{q}+G_{q}-B_{q 0}\right| \\
< & 2 u \varepsilon / 10 u+\Sigma_{q \in Q} \mid 1+F_{q}+G_{q}-\left[A_{q, n(q)+1}\right. \\
& \left.+\sum_{r=1}^{n(q)} A_{q r} G_{q r} B_{q r}\right] \mid \\
\leqq & \varepsilon / 5+\Sigma_{q \in Q}\left|1+F_{q}-A_{q, n(q)+1}\right| \\
& +\Sigma_{q \in Q}\left|G_{q}-\sum_{r=1}^{n(q)} A_{q r} G_{q r} B_{q r}\right| \\
< & 2 \varepsilon / 5+\Sigma_{q \in Q}\left|G_{q}-\sum_{r=1}^{n(q)} G_{q r}\right| \\
& +\Sigma_{q \in Q}\left|\sum_{r=1}^{n(q)} G_{q r}-\sum_{r=1}^{n(q)} A_{q r} G_{q r} B_{q r}\right| \\
< & 3 \varepsilon / 5+\Sigma_{q \in Q} \Sigma_{r=1}^{n(q)}\left|1-A_{q r}\right|\left|G_{q r}\right| \\
& +\sum_{q \in Q} \sum_{r=1}^{n(q)}\left|A_{q r}\right|\left|G_{q r}\right|\left|1-B_{q r}\right| \\
< & 3 \varepsilon / 5+(\varepsilon / 5 B) B+\left(\varepsilon / 5 B^{2}\right) B^{2}=\varepsilon
\end{aligned}
$$

Hence, if $a \leqq x<y \leqq b$ and $\varepsilon>0$, then there exist a subdivision $D$ of $[a, b]$ and a number $B$ such that if $H=\left\{x_{q}\right\}_{0}^{n}$ is a refinement of $D$ and $H_{q}$ is a subdivision of $\left[x_{q-1}, x_{q}\right]$, then

(1) $\left|\Pi_{i}^{j}\left(1+F_{q}+G_{q}\right)\right|<B$ for $1 \leqq i \leqq j \leqq n$, and

(2) $\Sigma_{1}^{n}\left|1+F_{q}+G_{q}-\Pi_{H_{q}(I)}(1+F+G)\right|<\varepsilon / B^{2}$.

Thus, if $H$ and $H_{q}$ are defined as above, then

$$
\begin{aligned}
& \left|\Pi_{1}^{n}\left(1+F_{q}+G_{q}\right)-\Pi_{1}^{n} \Pi_{H_{q}(I)}(1+F+G)\right| \\
& \quad \leqq B^{2} \Sigma_{1}^{n}\left|1+F_{q}+G_{q}-\Pi_{H_{q}(I)}(1+F+G)\right| \\
& \quad<B^{2}\left(\varepsilon / B^{2}\right)=\varepsilon .
\end{aligned}
$$

Therefore, ${ }_{x} \Pi^{y}(1+F+G)$ exists.

It now follows that $\int_{a}^{b}|1+F+G-\Pi(1+F+G)|=0$. Hence, $F+G \in O M^{\circ}$ on $[a, b]$.

Theorem 3. If $F \in O Q^{\circ}, G \in O B^{\circ}$ and $1+F+G$ is bounded away from zero on $[a, b]$, then $F+G \in O Q^{\circ}$ on $[a, b]$.

Proof. There exist a subdivision $D$ of $[a, b]$, a positive number $c<1$ and a positive integer $m$ such that if $J=\left\{x_{q}\right\}_{0}^{n}$ is a refinement of $D$, then

(1) $\left|1+F_{q}+G_{q}\right|>c$ for $1 \leqq q \leqq n$,

(2) $\left|\Pi_{i}^{j}\left(1+F_{q}\right)\right|>c$ for $1 \leqq i \leqq j \leqq n$, and

(3) if $K$ is any collection of nonintersecting subsets of $J(I)$, then the number of $k \in K$ such that $\Sigma_{k}|G| / c>1 / 2$ is less than $m$. Suppose $J=\left\{x_{q}\right\}_{0}^{n}$ is a refinement of $D$ and $1 \leqq r \leqq s \leqq n$. Let $K=$ $\left\{k_{j}\right\}$ be the collection of nonintersecting subsets of $\left\{\left[x_{q-1}, x_{q}\right]\right\}_{r}^{s}$ such that

(1) $k_{1}=\left\{\left[x_{q-1}, x_{q}\right]\right\}_{m(1)}^{n(1)}$, where $m(1)$ is the first integer such that $m(1) \geqq r$ and $\left|G_{m(1)}\right| / c \leqq 1 / 2$ and $n(1)$ is the largest integer such that $n(1)<s, \sum_{m(1)}^{n(1)}\left|G_{q}\right| / c \leqq 1 / 2$ and $\sum_{m(1)}^{n(1)+1}\left|G_{q}\right| / c>1 / 2$ if such an integer 
exists and $s$ otherwise, and

(2) $k_{j}=\left\{\left[x_{q-1}, x_{q}\right]\right\}_{m(j)}^{n(j)}$, where $m(j)$ is the first integer such that $m(j)>n(j-1)$ and $\left|G_{m(j)}\right| / c<1 / 2$ and $n(j)$ is the largest integer such that $n(j) \leqq s, \sum_{m(j)}^{n(j)}\left|G_{q}\right| / c \leqq 1 / 2$ and $\sum_{m(j)}^{n(j)+1}\left|G_{q}\right| / c>1 / 2$ if such an integer exists and $s$ otherwise.

Let $U=\bigcup_{k \in K} k$ and $V=\left\{\left[x_{q-1}, x_{q}\right]\right\}_{r}^{s}-U$. Note that $K$ and $V$ each has a maximum of $m$ elements. Thus,

$$
\begin{aligned}
& \left|\Pi_{r}^{s}\left(1+F_{q}+G_{q}\right)\right| \\
& \quad=\left\{\Pi_{V}|1+F+G|\right\}\left\{\Pi_{U}|1+F+G|\right\} \\
& \quad \geqq c^{m} \Pi_{U}[|1+F|-|G|] \\
& \quad=c^{m} \Pi_{k \in K}\left\{\Pi_{k}|1+F|\right\}\left\{\Pi_{k}\left[1-|G|(|1+F|)^{-1}\right]\right\} \\
& \quad \geqq c^{2 m} \Pi_{k \in K}\left\{\Pi_{k}(1-|G| / c)\right\} \\
& \quad \geqq c^{2 m} \Pi_{k \in K}\left[1-\Sigma_{k}|G| / c\right] \geqq c^{2 m} / 2^{m} .
\end{aligned}
$$

COROLLARY 3.1. If $\int_{a}^{b} F$ exists, then the following are equivalent: (1) $F \in O Q^{\circ}$ on $[a, b]$, and (2) $\int F \in O Q^{\circ}$ on $[a, b]$.

Indication of proof. Since $\int_{a}^{b} F$ exists, $F \in O A^{\circ}$ [Lemma 1.1]. The result now follows by using Theorem 3 .

COROLLARY 3.2. If $G$ is a function, then the following are equivalent: (1) $G \in O Q^{1}$ on $[a, b]$, and (2) if $F \in O B^{\circ}$ on $[a, b]$, then $F+$ $G \in O Q^{1}$ on $[a, b]$.

Indication of proof. Since $F \equiv 0$ is in $O B^{\circ}$, (2) implies (1). Further, it follows from Theorem 3 that (1) implies (2).

Lemma 3.1. If $0 \leqq G \leqq 1$ and $G \notin O B^{\circ}$ on $[a, b]$, then $-G \notin O Q^{\circ}$ on $[a, b]$.

Indication of proof. If $H$ is a subdivision of $[a, b]$, then

$$
\begin{aligned}
\Pi_{H(I)}(1-G) & =\exp \left[\Sigma_{H(I)} \ln (1-G)\right] \\
& =\exp \left[-\Sigma_{H(I)} \Sigma_{1}^{\infty} G^{i} / i\right] .
\end{aligned}
$$

Thus, $\Pi_{H(I)}(1-G) \rightarrow 0$ as $\Sigma_{H(I)} G \rightarrow \infty$.

COROLLARY 3.3. If $G$ is a function, then the following are equivalent: (1) $G \in O B^{\circ}$ on $[a, b]$, and (2) if $F \in O Q^{1}$ on $[a, b]$, then $F+$ $G \in O Q^{1}$ on $[a, b]$. 
Proof. Since it follows from Theorem 3 that (1) implies (2), we need only show that (2) implies (1). The function $|G|$ is almost bounded above on $[a, b]$ by $1 / 2$. If this is not so, then a contradiction follows by considering the function $F$ such that

(1) $F(x, y)=0$ if $-1 / 2 \leqq G(x, y) \leqq 0$,

(2) $F(x, y)=-G(x, y)-1 / 2$ if $G(x, y)<-1 / 2$,

(3) $F(x, y)=-2$ if $0<G(x, y) \leqq 1 / 2$, and

(4) $F(x, y)=-G(x, y)-3 / 2$ if $G(x, y)>1 / 2$.

Thus, although $F \in O Q^{1}, F+G \notin O Q^{1}$ since $|1+F+G| \leqq 1$ and the number of intervals for which $|1+F+G|=1 / 2$ is unbounded. Now, if $G \notin O B^{\circ}$, a contradiction follows from Lemma 3.1 by using the function $F$ such that

(1) $F(x, y)=-2$ if $G(x, y) \geqq 0$, and

(2) $F(x, y)=0$ if $G(x, y)<0$.

THEOREM 4. If $G$ is a function, then the following are equivalent:

(1) if $\int_{a}^{b}|F|=0$, then $F G \in O B^{\circ}$,

(2) if $\int_{a}^{b}|F|=0$, then $F G \in O P^{\circ}$,

(3) if $\int_{a}^{b}|F|=0$, then $F G \in O Q^{\circ}$, and

(4) $G$ is bounded on $[a, b]$.

Proof. It follows readily that (4) implies (1). Further, it follows that (4) implies (2) and (3) by using Theorems 1 and 3, respectively. If $G(x, y)$ as $x, y \rightarrow p^{-}, G(x, y)$ as $x, y \rightarrow p^{+}, G(x, p)$ as $x \rightarrow p^{-}$and $G(p, x)$ as $x \rightarrow p^{+}$are bounded for each $p \in[a, b]$, then it follows from the covering theorem that $G$ is bounded on $[a, b]$. If one or more of these bounds fail to exist for some $p \in[a, b]$, then there exists a sequence $\left\{\left(y_{q}, z_{q}\right)\right\}_{1}^{\infty}$ of distinct subintervals of $[a, b]$ such that $\left|G\left(y_{q}, z_{q}\right)\right|>$ $q^{3}$ for $q=1,2, \cdots$, and if $\left\{x_{q}\right\}_{0}^{n}$ is a subdivision of $[a, b]$ and $r$ is a positive integer then there exist positive integers $i$ and $j$ such that $j>r$ and $x_{i-1} \leqq y_{j}<z_{j} \leqq x_{i}$. Contradictions to (1) and (2) now follow by considering the function $F$ such that

$$
F(x, y)=[G(x, y)] /\left[q^{2}|G(x, y)|\right]
$$

if there exists a positive integer $q$ such that $x=y_{q}$ and $y=z_{q}$ and $F(x, y)=0$ otherwise. Here $\int_{a}^{b}|F|=0$, but $F G$ is in neither $O B^{\circ}$ nor $O P^{\circ}$. Further, a contradiction to (3) follows by considering the function $F$ such that $F(x, y)=[-G(x, y)]^{-1}$ if there exists a positive integer $q$ such that $x=y_{q}$ and $y=z_{q}$ and $F(x, y)=0$ otherwise. 
LEMma 5.1. If $G$ is a function such that

(1) $G$ is almost bounded above by $1 / 3$ on $[a, b]$, and

(2) if $F \in O P^{\circ}$ on $[a, b]$, then $F G \in O P^{\circ}$ on $[a, b]$, then $G \in O B^{\circ}$ on $[a, b]$.

Proof. Suppose $G \notin O B^{\circ}$ on $[a, b]$. It follows from Theorem 4 that $G$ is bounded on $[a, b]$. There exists a set $\{C(i)\}_{1}^{\infty}$ such that

(1) $C(i)$ is a finite set of nonoverlapping subintervals of $[a, b]$ which can be grouped into a collection $D(i)$ of nonintersecting pairs of adjacent intervals,

(2) no interval in $C(i+1)$ has an end point which is also the end point of an interval in $C(q), q=1,2, \cdots, i$,

(3) if $(x, y) \in C(i)$, then $G(x, y)<1 / 3$, and

(4) $\Sigma_{C(i)}|G|>i$.

Let $C=\bigcup_{1}^{\circ} D(i)$, and let $F$ be the function on $[a, b]$ such that if $\{(u, v),(r, s)\} \in C$ and $G(u, v) \geqq G(r, s)$, then

(a) $F(u, v)=-2$ if $G(u, v)<0$,

(b) $F(u, v)=2$ if $G(u, v) \geqq 0$,

(c) $F(r, x)=-1$ if $r=v$ and $r<x$, and

(d) $F(x, s)=-1$ if $s=u$ and $x<s$, and $F(x, y)=0$ otherwise. Thus, $F \in O P^{\circ}$ on $[a, b]$. However,

$$
[1+F(u, v) G(u, v)][1+F(r, s) G(r, s)] \geqq 1+|G(u, v)| / 3 .
$$

Hence, since $G$ is bounded and $\left\{\Sigma_{C(i)}|G|\right\}_{1}^{\infty}$ is unbounded, $F G \notin O P^{\circ}$. This is a contradiction, and therefore, $G \in O B^{\circ}$ on $[a, b]$.

LEMMA 5.2. If $G$ is a function such that

(1) $G$ is almost bounded below by $1 / 10$ on $[a, b]$, and

(2) if $F \in O P^{\circ}$ on $[a, b]$, then $F G \in O P^{\circ}$ on $[a, b]$, then $G-1 \in O B^{\circ}$ on $[a, b]$.

Proof. Suppose $G-1 \notin O B^{\circ}$ on $[a, b]$. It follows from Theorem 4 that $G$ is bounded on $[a, b]$. There exists a set $\{C(i)\}_{1}^{\infty}$ satisfying conditions (1) and (2) in Lemma 5.1 plus the additional conditions

(3) if $(x, y) \in C(i)$, then $G(x, y)>1 / 10$, and

(4) $\Sigma_{C(i)}|G-1|>i$.

Let $C=\bigcup_{1}^{\infty} D(i)$, where $D(i)$ is defined as in Lemma 5.1. Note that if $\{(u, v),(r, s)\} \in C$ and $G(u, v) \geqq G(r, s)$, then either

(5) $G(u, v) \geqq 1$ and $|1-G(u, v)| \geqq|1-G(r, s)|$, or

(6) $G(r, s)<1$ and either $G(u, v)=G(r, s)$ or

$$
|1-G(u, v)|<|1-G(r, s)| \text {. }
$$

Let $F$ be the function on $[a, b]$ such that if $\{(u, v),(r, s)\} \in C$ and $G(u, v) \geqq G(r, s)$, then 
(a) $F(u, v)=-2$ and $F(r, s)=0$ if (5) is true, $r<x$, and

(b) $F(u, v)=1$ and $F(r, x)=-1 / 2$ if (6) is true, $r=v$ and

(c) $F(u, v)=1$ and $F(x, s)=-1 / 2$ if (6) is true, $s=u$ and $x<s$,

and $F(x, y)=0$ otherwise. Thus, $F \in O P^{\circ}$ on $[a, b]$. Observe that if (5) is true, then

$$
[1+F(u, v) G(u, v)][1+F(r, s) G(r, s)]=-\{1+2[G(u, v)-1]\},
$$

and if (6) is true, then

$$
\begin{aligned}
{[1} & +F(u, v) G(u, v)][1+F(r, s) G(r, s)] \\
& \geqq[1+G(r, s)][1-G(r, s) / 2] \\
& >1+[1 / 20][1-G(r, s)] .
\end{aligned}
$$

Hence, since $G$ is bounded and $\left\{\Sigma_{C(i)}|G-1|\right\}_{1}^{\infty}$ is unbounded, $F G \notin O P^{\circ}$. This is a contradiction, and therefore, $G-1 \in O B^{\circ}$ on $[a, b]$.

THEOREM 5. If $G$ is a function, then the following are equivalent:

(1) $G \in O B^{*}$ on $[a, b]$, and

(2) if $F \in O P^{\circ}$ on $[a, b]$, then $F G \in O P^{\circ}$ on $[a, b]$.

Proof $(2 \rightarrow 1)$. If $a \leqq \alpha<b$, then there exists a number $\beta$ such that $\alpha<\beta \leqq b$ and either $G \in O B^{\circ}$ on $[\alpha, \beta]$ or $G-1 \in O B^{\circ}$ on $[\alpha, \beta]$. If this is false and $a \leqq \alpha<\beta<b$, then it follows from Lemmas 5.1 and 5.2 that $G$ is neither almost bounded above by $1 / 3$ nor almost bounded below by $1 / 10$ on $[\alpha, \beta]$; hence, there exist sequences $\left\{s_{p}\right\}_{1}^{\infty}$ and $\left\{r_{p}\right\}_{1}^{\infty}$ such that

(1) $s_{p}$ and $r_{p}$ are subintervals of $[a, b]$ with a common end point,

(2) $s_{p}$ precedes $r_{p}$ and $r_{p+1}$ precedes $s_{p}$, and

(3) $G\left(s_{p}\right)<1 / 10$ and $G\left(r_{p}\right) \geqq 1 / 10$.

Let $H=\left\{s_{p}\right\}_{1}^{\infty} \cup\left\{r_{p}\right\}_{1}^{\infty}$, and let $F$ be the function on $[a, b]$ such that

(1) $F(x, y)=-1$ if there exists an interval $(z, y) \in H$ such that $x<y$ and $G(z, y)<1 / 10$,

(2) $F(x, y)=2$ if $(x, y) \in H$ and $G(x, y) \geqq 1 / 10$, and

(3) $F(x, y)=0$ otherwise.

Thus, $F \in O P^{\circ}$ on $[a, b]$. However, it follows that $F G \notin O P^{\circ}$ on $[a, b]$ since

$$
\left[1+F\left(s_{p}\right) G\left(s_{p}\right)\right]\left[1+F\left(r_{p}\right) G\left(r_{p}\right)\right]>(.9)(1.2)=1.08 \text {. }
$$

Similarly, if $a<\beta \leqq b$, then there exists a number $\alpha$ such that $\alpha \leqq \alpha<\beta$ and either $G \in O B^{\circ}$ on $[\alpha, \beta]$ or $G-1 \in O B^{\circ}$ on $[\alpha, \beta]$. It now follows that $G \in O B^{*}$ on $[a, b]$ by using the covering theorem. 
Proof $(1 \rightarrow 2)$. Since $O B^{\circ} \cong O P^{\circ}$, if $G \in O B^{\circ}$ and $F \in O P^{\circ}$ on $[x, y]$, then $F G \in O P^{\circ}$ on $[x, y]$. Note that

$$
1+F G=1+F+F(G-1) .
$$

Thus, it follows from Theorem 1 that if $G-1 \in O B^{\circ}$ and $F \in O P^{\circ}$ on $[x, y]$, then $F G \in O P^{\circ}$ on $[x, y]$. Therefore, (1) must imply (2). alent:

Corollary 5.1. If $G$ is a function, then the following are equiv-

(1) $G \in O P^{\circ}$ on $[a, b]$, and

(2) if $F \in O B^{*}$ on $[a, b]$, then $F G \in O P^{\circ}$ on $[a, b]$.

Indication of proof. It follows that (1) implies (2) by using Theorem 5 and that (2) implies (1) by considering the function $F \equiv 1$.

LEMMA 6.1. If $G$ is a bounded function such that

(1) $G$ is almost bounded above by $1 / 3$ on $[a, b]$, and

(2) if $F \in O Q^{\circ}$ and is bounded on $[a, b]$ and $1+F G$ is bounded away from zero, then $F G \in O Q^{\circ}$ on $[a, b]$,

then $G \in O B^{\circ}$ on $[a, b]$.

Proof. Suppose $G \notin O B^{\circ}$ on $[a, b]$. There exist a subdivision $D$ of $[a, b]$ and a positive integer $m$ such that if $J$ is a refinement of $D$ and $u \in J(I)$ then $|G(u)| / m<1 / 2$. Let $H$ be the set such that $u \in H$ only if there exists a refinement $J$ of $D$ such that $u \in J(I)$, and let $F$ be the function such that

(1) $F(u)=-2$ if $u \in H$ and $0 \leqq G(u) \leqq 1 / 3$,

(2) $F(u)=1 / m$ if $u \in H$ and $G(u)<0$, and

(3) $F(x, y)=0$ otherwise.

Since $F \in O Q^{\circ}$ and $1+F G$ is bounded away from zero, $F G \in O Q^{\circ}$. However, it follows from Lemma 3.1 that $F G \notin O Q^{\circ}$. This is a contradiction, and therefore, $G \in O B^{\circ}$.

LEMMA 6.2. If $G$ is a bounded function such that

(1) $G$ is almost bounded below by $1 / 10$ on $[a, b]$, and

(2) if $F \in O Q^{\circ}$ and is bounded on $[a, b]$ and $1+F G$ is bounded away from zero, then $F G \in O Q^{\circ}$ on $[a, b]$, then $G-1 \in O B^{\circ}$ on $[a, b]$.

Proof. There exist a subdivision $D$ of $[a, b]$ and a number $B$ such that if $J$ is a refinement of $D$ and $u \in J(I)$ then $|G(u)|<B$. Let $H$ be the set such that $u \in H$ only if there exists a refinement $J$ of $D$ such that $u \in J(I)$. Let $H_{1}$ and $H_{2}$ be the subsets of $H$ such that $u \in H_{1}$ only if $G(u) \leqq 1$ and $u \in H_{2}$ only if $G(u)>1$. For $i=1,2$, let $G_{i}(x, y)=G(x, y)$ if $(x, y) \in H_{i}$ and $G_{i}(x, y)=0$ if $(x, y) \notin H_{i}$. 
Suppose $G_{1}-1 \notin O B^{\circ}$ on $[a, b]$. Let $F$ be the function such that

(1) $F(u)=-2$ if $u \in H_{1}$ and $G(u)<5 / 12$ or $7 / 12<G(u) \leqq 1$,

(2) $F(u)=-3$ if $u \in H_{1}$ and $5 / 12 \leqq G(u) \leqq 7 / 12$, and

(3) $F(x, y)=0$ otherwise.

Since $F \in O Q^{\circ}$ and $1+F G$ is bounded away from zero, $F G \in O Q^{\circ}$. However, it follows from Lemma 3.1 that $F G \notin O Q^{\circ}$. This is a contradiction, and therefore, $G_{1}-1 \in O B^{\circ}$.

Suppose $G_{2}-1 \notin O B^{\circ}$ on $[a, b]$. There exist a set $\{C(i)\}_{1}^{\infty}$ and an integer $m>1$ such that

(1) $C(i)$ is a finite set of nonoverlapping subintervals of $[a, b]$ which can be grouped into a collection $D(i)$ of nonintersecting pairs $\{(u, v),(r, s)\}$ of adjacent intervals such that either $G(u, v)>1$ or $G(r, s)>1$,

(2) no interval in $C(i+1)$ has an end point which is also the end point of an interval in $C(q), q=1,2, \cdots, i$,

(3) if $(x, y) \in C(i)$ then $G(x, y)>1 / 10$ and $G(x, y) / m<1 / 2$, and

(4) $\Sigma_{C(i)}\left|G_{2}-1\right|>i$.

Let $C=\bigcup_{1}^{\infty} D(i)$, and let $F$ be the function such that if $\{(u, v),(r, s)\} \in C$ and $G(u, v) \geqq G(r, s)$ then $F(u, v)=-1 / m, F(r, x)=1 /(m-1)$ if $r=v$ and $F(x, s)=1 /(m-1)$ if $s=u$, and $F(x, y)=0$ otherwise. Since $F \in O Q^{\circ}$ and $1+F G$ is bounded away from zero, $F G \in O Q^{\circ}$. However, if $\{(u, v),(r, s)\} \in C$ and $G(u, v) \geqq G(r, s)$, then

$$
\begin{aligned}
0 & <[1+F(u, v) G(u, v)][1+F(r, s) G(r, s)] \\
& \leqq[1-G(u, v) / m][1+G(u, v) /(m-1)] \\
& <1+[1-G(u, v)] / m(m-1) .
\end{aligned}
$$

It follows from Lemma 3.1 that $F G \notin O Q^{\circ}$. This is a contradiction, and therefore, $G_{2}-1 \in O B^{\circ}$.

Thus, since $G_{i}-1 \in O B^{\circ}$ on $[a, b]$ for $i=1,2$, it follows that $G-1 \in O B^{\circ}$ on $[a, b]$.

THEOREM 6. If $G$ is a bounded function, then the following are equivalent:

(1) $G \in O B^{*}$ on $[a, b]$, and

(2) if $F \in O Q^{\circ}$ and is bounded on $[a, b]$ and $1+F G$ is bounded away from zero, then $F G \in O Q^{\circ}$ on $[a, b]$.

Proof $(2 \rightarrow 1)$. If $a \leqq \alpha<b$, then there exists a number $\beta$ such that $\alpha<\beta \leqq b$ and either $G \in O B^{\circ}$ on $[\alpha, \beta]$ or $G-1 \in O B^{\circ}$ on $[\alpha, \beta]$. If this is false, then it follows from Lemmas 6.1 and 6.2 that there exist sequences $\left\{s_{p}\right\}_{1}^{\infty}$ and $\left\{r_{p}\right\}_{1}^{\infty}$ and a set $H$ defined as in Theorem 5. Let $F$ be a function on $[a, b]$ such that if $(u, v)$ and $(v, s)$ are intervals in $H$ such that $G(u, v) \leqq 1 / 10$ and $G(v, s) \geqq 1 / 10$, then 
(1) $1+F(u, v) G(u, v)=1 / 2$ and $F(v, s)=0$ if $G(u, v)<-1 / 10$,

(2) $F(x, v)=1,-1 / 2 \leqq F(v, s)<0$ and $1 / 2 \leqq 1+F(v, s) G(v, s) \leqq$ .95 if $-1 / 10 \leqq G(u, v) \leqq 0$, and

(3) $\quad F(x, v)=-3,-1 / 2 \leqq F(v, s)<0$ and $1 / 2 \leqq 1+F(v, s) G(v, s) \leqq$ .95 if $0<G(u, v)<1 / 10$,

and $F(x, y)=0$ otherwise. Since $F$ is a bounded function in $O Q^{\circ}$ such that $1+F G$ is bounded away from zero, $F G \in O Q^{\circ}$. However,

$$
\left|\left[1+F\left(s_{p}\right) G\left(s_{p}\right)\right]\left[1+F\left(r_{p}\right) G\left(r_{p}\right)\right]\right| \leqq .95 .
$$

Hence, $F G \notin O Q^{\circ}$. Similarly, if $a<\beta \leqq b$, then there exists a number $\alpha$ such that $a \leqq \alpha<\beta$ and either $G \in O B^{\circ}$ on $[\alpha, \beta]$ or $G-1 \in O B^{\circ}$ on $[\alpha, \beta]$. It now follows that $G \in O B^{*}$ on $[\alpha, b]$ by using the covering theorem.

Proof $(1 \rightarrow 2)$. This follows from Theorem 3 by a procedure similar to that used in Theorem 5 .

\section{REFERENCES}

1. W. D. L. Appling, Interval functions and real Hilbert spaces, Rend. Circ. Mat. Palermo, Series 2, 11 (1962), 154-156.

2. B. W. Helton, Integral equations and product integrals, Pacific J. Math., 16 (1966), 297-322.

3. A. Kolmogoroff, Untersuchungen über den Integralbegriff, Math. Ann., 103 (1930), 654-696.

4. J. S. MacNerney, Integral equations and semigroups, Illinois J. Math., 7 (1963), 148-173.

Received May 10, 1972.

ARIZONa STATE UNIVERSITY 



\section{PACIFIC JOURNAL OF MATHEMATICS}

\section{EDITORS}

RICHARD ARENS (Managing Editor)

University of California

Los Angeles, California 90024

\section{R. A. Beaumont}

University of Washington

Seattle, Washington 98105

\section{J. DuGundJI*}

Department of Mathematics

University of Southern California

Los Angeles, California 90007

D. Gilbarg and J. Milgram

Stanford University

Stanford, California 94305

ASSOCIATE EDITORS
E. F. BECKENBACH
B. H. NeumanN
F. WOLF
K. YoSHIDA

\section{SUPPORTING INSTITUTIONS}

UNIVERSITY OF BRITISH COLUMBIA

CALIFORNIA INSTITUTE OF TECHNOLOGY

UNIVERSITY OF CALIFORNIA

MONTANA STATE UNIVERSITY

UNIVERSITY OF NEVADA

NEW MEXICO STATE UNIVERSITY

OREGON STATE UNIVERSITY

UNIVERSITY OF OREGON

OSAKA UNIVERSITY

\author{
UNIVERSITY OF SOUTHERN CALIFORNIA \\ STANFORD UNIVERSITY \\ UNIVERSITY OF TOKYO \\ UNIVERSITY OF UTAH \\ WASHINGTON STATE UNIVERSITY \\ UNIVERSITY OF WASHINGTON \\ AMERICAN MATHEMATICAL SOCIETY \\ NAVAL WEAPONS CENTER
}

The Supporting Institutions listed above contribute to the cost of publication of this Journal, but they are not owners or publishers and have no responsibility for its content or policies.

Mathematical papers intended for publication in the Pacific Journal of Mathematics should be in typed form or offset-reproduced, (not dittoed), double spaced with large margins. Underline Greek letters in red, German in green, and script in blue. The first paragraph or two must be capable of being used separately as a synopsis of the entire paper. Items of the bibliography should not be cited there unless absolutely necessary, in which case they must be identified by author and Journal, rather than by item number. Manuscripts, in duplicate if possible, may be sent to any one of the four editors. Please classify according to the scheme of Math. Rev. Index to Vol. 39. All other communications to the editors should be addressed to the managing editor, or Elaine Barth, University of California, Los Angeles, California, 90024.

50 reprints are provided free for each article; additional copies may be obtained at cost in multiples of 50 .

The Pacific Journal of Mathematics is issued monthly as of January 1966. Regular subscription rate: $\$ 48.00$ a year (6 Vols., 12 issues). Special rate: $\$ 24.00$ a year to individual members of supporting institutions.

Subscriptions, orders for back numbers, and changes of address should be sent to Pacific Journal of Mathematics, 103 Highland Boulevard, Berkeley, California, 94708.

\section{PUBLISHED BY PACIFIC JOURNAL OF MATHEMATICS, A NON-PROFIT CORPORATION}

Printed at Kokusai Bunken Insatsusha (International Academic Printing Co., Ltd.), 270, 3-chome Totsuka-cho, Shinjuku-ku, Tokyo 160, Japan.

* C. R. DePrima California Institute of Technology, Pasadena, CA 91109, will replace J. Dugundji until August 1974.

Copyright (C) 1973 by

Pacific Journal of Mathematics

All Rights Reserved 


\section{Pacific Journal of Mathematics}

\section{Vol. 49, No. $2 \quad$ June, 1973}

Wm. R. Allaway, On finding the distribution function for an orthogonal polynomial

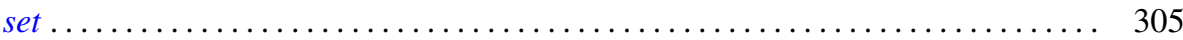

Eric Amar, Sur un théorème de Mooney relatif aux fonctions analytiques bornées... . 311

Robert Morgan Brooks, Analytic structure in the spectrum of a natural system . . . . 315

Bahattin Cengiz, On extremely regular function spaces . . . . . . . . . . . . . . 335

Kwang-nan Chow and Moses Glasner, Atoms on the Royden boundary . . . . . . . . . 339

Paul Frazier Duvall, Jr. and Jim Maxwell, Tame $Z^{2}$-actions on $E^{n} \ldots \ldots \ldots \ldots \ldots . .349$

Allen Roy Freedman, On the additivity theorem for $n$-dimensional asymptotic

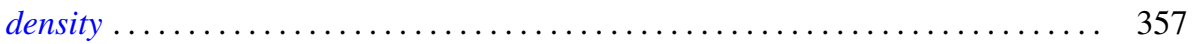

John Griffin and Kelly Denis McKennon, Multipliers and the group $L_{p}$-algebras . . . 365

Charles Lemuel Hagopian, Characterizations of $\lambda$ connected plane continua ....... 371

Jon Craig Helton, Bounds for products of interval functions . . . . . . . . . . . 377

Ikuko Kayashima, On relations between Nörlund and Riesz means . . . . . . . . . . 391

Everett Lee Lady, Slender rings and modules . . . . . . . . . . . . . . . . . . 397

Shozo Matsuura, On the Lu Qi-Keng conjecture and the Bergman representative

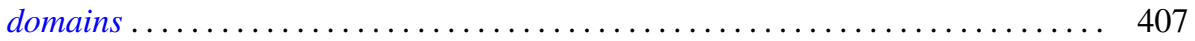

Stephen H. McCleary, The lattice-ordered group of automorphisms of an $\alpha$-set . . . 417

Stephen H. McCleary, o-2-transitive ordered permutation groups .......... 425

Stephen H. McCleary, o-primitive ordered permutation groups. II . . . . . . . . . 431

Richard Rochberg, Almost isometries of Banach spaces and moduli of planar

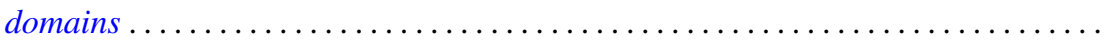

R. F. Rossa, Radical properties involving one-sided ideals . . . . . . . . . . . . . 467

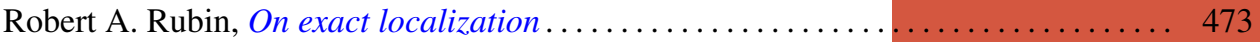

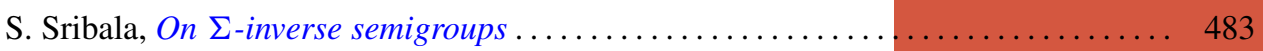

H. M. (Hari Mohan) Srivastava, On the Konhauser sets of biorthogonal polynomials suggested by the Laguerre polynomials ...................... 489

Stuart A. Steinberg, Rings of quotients of rings without nilpotent elements . ...... 493

Daniel Mullane Sunday, The self-equivalences of an $H$-space . . ............ 507

W. J. Thron and Richard Hawks Warren, On the lattice of proximities of $\check{C} e c h$

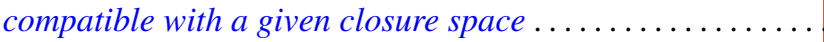

Frank Uhlig, The number of vectors jointly annihilated by two real quadratic forms determines the inertia of matrices in the associated pencil .

Frank Uhlig, On the maximal number of linearly independent real vectors annihilated simultaneously by two real quadratic forms ..............

Frank Uhlig, Definite and semidefinite matrices in a real symmetric matrix pencil . . 561

Arnold Lewis Villone, Self-adjoint extensions of symmetric differential operators . . . 569

Cary Webb, Tensor and direct products . ....................... 579

James Victor Whittaker, On normal subgroups of differentiable

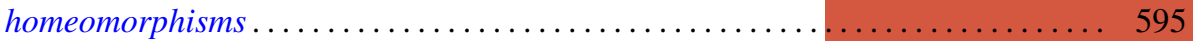

Jerome L. Paul, Addendum to: "Sequences of homeomorphisms which converge to

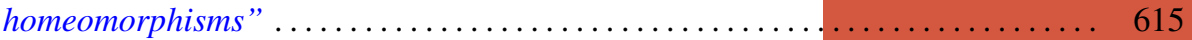

David E. Fields, Correction to: “Dimension theory in power series rings” ........ 616

Peter Michael Curran, Correction to: “Cohomology of finitely presented groups”. . . 617

Billy E. Rhoades, Correction to: “Commutants of some Hausdorff matrices” ...... 617

Charles W. Trigg, Corrections to: "Versum sequences in the binary system” ...... 619 